\title{
WEIGHTED INEQUALITIES FOR FRACTIONAL INTEGRAL OPERATORS WITH KERNEL SATISFYING HÖRMANDER TYPE CONDITIONS
}

\author{
Ana L. Bernardis, María Lorente And María Silvina Riveros
}

Abstract. In this paper we study inequalities with weights for fractional operators $T_{\alpha}$ given by convolution with a kernel $K_{\alpha}$ which is supposed to satisfy some size condition and a fractional Hörmander type condition. As it is done for singular integrals, the conditions on the kernel have been generalized from the scale of Lebesgue spaces to that of Orlicz spaces. Our fractional operators include as particular cases the classical fractional integral $I_{\alpha}$, fractional integrals associated to an homogeneous function and fractional integrals given by a Fourier multiplier.

Mathematics subject classification (2010): 42B20, 42B25.

Keywords and phrases: Fractional operators, Hörmander's condition of Young type, Muckenhoupt weights, two-weight estimates,commutators, BMO.

\section{REFERENCES}

[1] A. Bernardis, S. Hartzstein And G. PRAdolini, Weighted inequalities for commutators of fractional integrals on spaces of homogeneous type, J. Math. Anal. Appl., 322 (2006), 825-846.

[2] A.L. BernARDis, M. LoRENTE, Sharp two weight inequalities for commutators of RiemannLiouville and Weyl fractional integral operator, Integr. Equat. Oper. Th., 61 (2008), 449-475.

[3] A.L. Bernardis, M. Lorente, G. Pradolini, M.S. Riveros, Composition of fractional Orlicz. maximal operators and $A_{1}$-weights on spaces of homogeneous type, preprint.

[4] S. Chanillo, D.K. Watson and R.L. Wheeden, Some integral and maximal operators related to starlike sets, Studia Math., 107, 3 (1993), 223-255.

[5] R. Coifman, Distribution function inequalities for singular integrals, Proc. Acad. Sci. U.S.A., 69 (1972), 2838-2839.

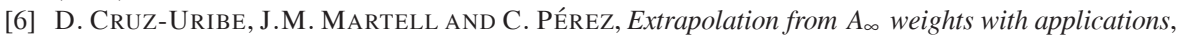
J. Funct. Anal., 213 (2004), 412-439.

[7] Y. DING AND S. LU, Weighted norm inequalities for fractional integral operators with rough kernel, Can. J. Math., 50, 1 (1998), 29-39.

[8] C. FefFerman And E.M. Stein, $H^{p}$ spaces in several variables, Acta Math., 129 (1972), $137-193$.

[9] D.S. KURTZ, Sharp function estimates for fractional integrals and related operators, J. Austral. Math. Soc. A, 49 (1990), 129-137.

[10] D.S. KuRTZ AND R.L. WheEden, Results on weighted norm inequalities for multipliers, Trans. Amer. Math. Soc., 255 (1979), 343-362.

[11] M. Lorente, J.M. Martell, M.S. Riveros and A. DE LA Torre, Generalized Hörmander's condition, commutators and weights, J. Math. Anal. Appl., 342 (2008), 1399-1425.

[12] M. Lorente, M.S. Riveros AND A. DE LA TORRE, Weighted estimates for singular integral operators satisfying Hörmander's conditions of Young type, J. Fourier Anal. Apl., 11, 5 (2005), 497-509.

[13] B. Muckenhoupt And R. L. WheEden, Weighted norm inequalities for fractional integrals, Trans. Amer. Math. Soc., 192 (1974), 261-274.

[14] R. O’NeIL, Fractional integration in Orlicz spaces, Trans. Amer. Math. Soc., 115 (1963), 300-328.

[15] C. PÉREZ, Weighted norm inequalities for singular integral operators, J. London Math. Soc., 49 (1994), 296-308.

[16] C. PÉREZ, Sharp estimates for commutators of singular integrals via iterations of the HardyLittlewood maximal function, J. Fourier Anal. Appl., 3, 6 (1997), 743-756. 
[17] C. PÉREZ, On sufficient conditions for the boundedness of the Hardy-Littlewood maximal operator between weighted $L^{p}$-spaces with different weights, Proc. London Math. Soc., 71, 3 (1995), $135-157$.

[18] C. PÉREZ, Sharp $L^{p}$-weighted Sobolev inequalities, Ann. Inst. Fourier (Grenoble), 45, 3 (1995), 809824.

[19] M. RaO AND Z.D. REN, Theory of Orlicz spaces, Monographs and Textbooks in Pure and Applied Mathematics, 146, Marcel Dekker, Inc., New York, 1991.

[20] J.L. Rubio De Francia, F.J. Ruiz And J. L. TorRea, Calderón-Zygmund theory for vectorvalued functions, Adv. in Math., 62 (1986), 7-48.

[21] C. Segovia And J.L. TorReA, Higher order commutators for vector-valued Calderón-Zygmund operators, Trans. Amer. Math. Soc., 336 (1993), 537-556. 